\title{
Brain-Specific Knock-Out of Hypoxia-Inducible Factor-1 $\alpha$ Reduces Rather Than Increases Hypoxic-Ischemic Damage
}

\author{
Rob Helton, ${ }^{1 *}$ Jiankun Cui, ${ }^{2 \star}$ John R. Scheel, ${ }^{1 *}$ Julie A. Ellison, ${ }^{1}$ Chris Ames, ${ }^{1}$ Claire Gibson, ${ }^{2}$ Barbara Blouw, ${ }^{3}$ \\ Ling Ouyang, ${ }^{1}$ Ioannis Dragatsis, ${ }^{4}$ Scott Zeitlin, ${ }^{5}$ Randall S. Johnson, ${ }^{3}$ Stuart A. Lipton, ${ }^{2}$ and Carrolee Barlow ${ }^{1}$ \\ ${ }^{1}$ Laboratory of Genetics, The Salk Institute for Biological Studies, and ${ }^{2}$ Center for Neuroscience and Aging, The Burnham Institute, La Jolla, California \\ 92037, ${ }^{3}$ Molecular Biology Section, Division of Biology, University of California, San Diego, La Jolla, California 92093, ${ }^{4}$ Department of Physiology, The \\ University of Tennessee, Health Science Center, Memphis, Tennessee 38163, and ${ }^{5}$ Department of Neuroscience, University of Virginia School of Medicine, \\ Charlottesville, Virginia 22908
}

Hypoxia-inducible factor- $1 \alpha$ (HIF-1 $\alpha$ ) plays an essential role in cellular and systemic $\mathrm{O}_{2}$ homeostasis by regulating the expression of genes important in glycolysis, erythropoiesis, angiogenesis, and catecholamine metabolism. It is also believed to be a key component of the cellular response to hypoxia and ischemia under pathophysiological conditions, such as stroke. To clarify the function of HIF- $1 \alpha$ in the brain, we exposed adult mice with late-stage brain deletion of HIF- $1 \alpha$ to hypoxic injuries. Contrary to expectations, the brains from the HIF-1 $\alpha$-deficient mice were protected from hypoxia-induced cell death. These surprising findings suggest that decreasing the level of HIF- $1 \alpha$ can be neuroprotective. Gene chip expression analysis revealed that, contrary to expectations, the majority of hypoxia-dependent gene-expression changes were unaltered, whereas a specific downregulation of apoptotic genes was observed in the HIF- $1 \alpha$-deficient mice. Although the role of HIF- $1 \alpha$ has been extensively characterized in vitro, in cancer models, and in chronic preconditioning paradigms, this is the first study to evaluate the role of HIF- $1 \alpha$ in vivo in the brain in response to acute hypoxia/ischemia. Our data suggest, that in acute hypoxia, the neuroprotection found in the HIF-1 $\alpha$-deficient mice is mechanistically consistent with a predominant role of HIF- $1 \alpha$ as proapoptotic and loss of function leads to neuroprotection. Furthermore, our data suggest that functional redundancy develops after excluding HIF- $1 \alpha$, leading to the preservation of gene expression regulating the majority of other previously characterized HIF-dependent genes.

Key words: apoptosis; carotid; hippocampus; hypoxia; neuron; transcription

\section{Introduction}

The ability of cells and an organism to adapt to periods of hypoxia is important for their survival in both physiological and pathophysiological states (Bunn and Poyton, 1996). Hypoxia inducible factor-1 (HIF-1) is a basic helix-loop-helix (HLH) heterodimeric transcription factor that is thought to play a major role in the response to hypoxia (Semenza, 2000). HIF-1 consists of a consti-

Received Nov. 5, 2004; revised Feb. 17, 2005; accepted Feb. 18, 2005.

This work was supported by the Frederick B. Rentschler Developmental Chair, National Institute of Neurological Disorders and Stroke Grant NS039601-04 (C.B.), National Institutes of Health (NIH) Grants F31 NS10860-01 (J.R.S.), P01 HD29587, R01 EY05477, R01 NS47973, R01 NS44326, R01 NS46994, and R01 NS43242, an Ellison Medical Foundation Senior Scholar Award (S.A.L.), and Microarray Core support by NIH Cancer Core Grant CA014195 (L.O.). We acknowledge the following: David Lockhart for scientific insights and support of this project; David and Dan Lockhart for programming of the BullFrog software; Information Management Consultants (McLean, VA) and Teradata (NCR, Dayton, $\mathrm{OH}$ ) for donating the Teradata database and programming of the Teragenomics database; Ingenuity Systems for donation of the software and for figure preparation; Donna Ferriero and Howard Federoff for scientific insights and support of this project; Kathy Chung and Emily Annas for assistance with Q-PCR analysis; Peter Wagner for the use of the hypoxia chamber; and GOTree for analysis and programming. Additionally, we thank C. Doane and Jamie Simon for assistance with preparation of this manuscript.

*R.H., J.C., and J.R.S. contributed equally to this work.

Correspondence should be addressed to either of the following: Carrolee Barlow, Laboratory of Genetics, The Salk Institute for Biological Studies, 10100 North Torrey Pines Road, La Jolla, CA 92037, E-mail: barlow@salk.edu or cbarlow@braincellsinc.com; or Stuart A. Lipton, Center for Neuroscience and Aging, The Burnham Institute, 10901 North Torrey Pines Road, La Jolla, CA 92037, E-mail: slipton@burnham.org.

D01:10.1523/JNEUROSCI.4555-04.2005

Copyright $\odot 2005$ Society for Neuroscience $\quad$ 0270-6474/05/254099-09\$15.00/0 tutively expressed subunit, HIF- $1 \beta$, and a subunit that is tightly regulated by the cellular $\mathrm{O}_{2}$ concentration, HIF- $1 \alpha$ (Wenger, 2002). HIF- $1 \alpha$ is the primary mammalian transcription factor specifically regulated by hypoxia; thus, HIF- $1 \alpha$ and the genes regulated by it have been the center of intense research because of their potential as therapeutic targets for ameliorating the effects of ischemia in a clinical setting.

HIF- $1 \alpha$ regulates genes that are important in tissue survival, such as vascular endothelial growth factor (VEGF), which has been shown to induce vasculogenesis and angiogenesis in many organ systems. Although HIF-1 $\alpha$ is essential for adaptation to low oxygen levels, it has also been shown in vitro to mediate hypoxia-induced growth arrest and apoptosis (Goda et al., 2003). Genetic studies to evaluate more precisely the role of HIF- $1 \alpha$ in the organism had been hampered as a complete deletion leads to embryonic lethality (Ryan et al., 1998). Additional studies using animals with tissue and organ deletions during development have also been difficult to interpret because of developmental abnormalities (Ryan et al., 1998; Tomita et al., 2003).

To understand the function of HIF- $1 \alpha$ in the adult brain in response to acute hypoxia, we generated mice with a late-stage deletion of HIF- $1 \alpha$ in the brain and exposed them to acute hypoxic injuries (Dragatsis and Zeitlin, 2000). Surprisingly, mice deficient for HIF-1 $\alpha$ showed significantly less neuronal cell loss in 
response to hypoxia than control mice using two different paradigms of neuronal hypoxia. Furthermore, gene-expression data revealed that functional redundancy exists in the adult mouse brain, and the predominant role of HIF- $1 \alpha$ in acute hypoxia is proapoptotic.

\section{Materials and Methods}

Generation of mice. All animal procedures were performed according to protocols approved by The Salk Institute for Biological Studies and The Burnham Institute Animal Care and Use Committees. Mice with complete deletion of the HIF- $1 \alpha$ allele $\left(H I F-1 \alpha^{+/ \text {Neo }}\right)$ were generated by replacement with a neomycin resistance gene (NeoR) as described previously (Ryan et al., 1998). Mice that carried the conditional loxP alleles, $H I F-1 \alpha$ alleles flanked by loxP sites $\left(H I F-1 \alpha^{F / F}\right)$, were generated by engineering a loxP site in the first intron and a loxP-flanked NeoR cassette in the second intron as described previously (Ryan et al., 2000). Rlag\#5 mice expressing cAMP response element (CRE) under the control of the calcium/calmodulin-dependent kinase $\mathrm{CaMKII}_{\alpha}$-cre promoter $(C A M-$ $C R E$ ) were provided by Dr. Ioannis Dragatsis (University of Tennessee, Memphis, TN) (Dragatsis and Zeitlin, 2000). To generate mice with brain predominant HIF-1 $\alpha$ deletion $\left(H I F-1 \alpha^{\Delta / \Delta}\right)$, CAMCRE mice were bred to mice carrying the HIF- $1 \alpha^{F / F}$ alleles.

Genotyping. Tail snips were collected from mice at 2 weeks of age for genotyping. Tails were collected into lysis buffer, and DNA was isolated as described previously (Barlow et al., 1996). Genotyping was performed using PCR. HIF-1 $\alpha$ flox and wild-type (WT) alleles were detected using the following primers: HIF-24, GCA GTT AAG AGC ACT AGT TG; HIF-25, GGA GCT ATC TCT CTA GAC C; and HIF-26, TTG GGG TGA AAA CAT CTG C. The HIF- $1 \alpha$ Neo allele was identified using primers that detected the NeoR gene: $3^{\prime}$-TTC CTC CAG ATC ATC CTG ATC and 5'-AGA GGC TAT TCG GCT ATG ACT G. CAMCRE mice were identified using primers that detect the CRE gene: $5^{\prime}$-CCG GGC TCG CAC GAC CAA and 3'-GGC GCG GCA ACA CCA TTT TT. The products were run on a $1.5 \%$ agarose gel.

Determination of extent of deletion of HIF-1 $\alpha$. Mice were killed by cervical dislocation. A six-part brain dissection was done to isolate the cerebellum, cortex, hippocampus, hypothalamus, midbrain (minus the hypothalamus), and striatum. In addition, kidney, liver, skeletal muscle, spleen, and tail were collected. All tissues were snap frozen on dry ice and stored at $-80^{\circ} \mathrm{C}$ until use. On the next day, DNA was isolated, and later PCR or Southern blotting was performed. To detect the deleted HIF-1 $\alpha$ allele, primer GCA GTT AAG AGC ACT AGT TG for HIF-24 and primer TTG GGG TGA AAA CAT CTG C for HIF-26 were used. To quantify the amount of HIF-1 $\alpha$ deletion in HIF-1 $\alpha^{\Delta / \Delta}$ mice, a standard Southern blot was performed as described previously (Ryan et al., 2000). For the Southern blot, genomic DNA was isolated from different parts of the brain, and $15 \mu \mathrm{g}$ was digested with EcoRI and PstI. After blotting, the membrane was hybridized with a $700 \mathrm{bp}$ probe obtained from an EcoRI/BglII digest of pBSKHif1-a. The undeleted allele (HIF-1 $\alpha$ flox) band was represented by a $2.2 \mathrm{~kb}$ fragment, and the HIF-1 $\alpha \Delta$ band was represented by a $1.3 \mathrm{~kb}$ fragment.

Hypoxia induction. Mice were exposed to hypoxia in a normobaric chamber as described previously (Berg et al., 1998). $\mathrm{O}_{2}$ concentrations were regulated with nitrogen gas. The concentrations of $\mathrm{O}_{2}$ and $\mathrm{CO}_{2}$ were monitored continuously throughout the experiment as described previously (Berg et al., 1998). Mice were exposed to various levels of oxygen content (from 4 to $7 \%$ ) for times ranging from 0 to $4.5 \mathrm{~h}$ to determine optimal conditions. During the exposure, animals were visually monitored for the occurrence of seizures and/or other untoward events. All mice used in microarray experiments were exposed to $7 \% \mathrm{O}_{2}$.

Immunofluorescence. Mice used for immunofluorescence/histological studies were perfused with cold $4 \%$ paraformaldehyde transcardially. The brains were dissected and immersed in $20 \%$ sucrose for $2 \mathrm{~d}$ before microtome sectioning $(40 \mu \mathrm{m})$. Cell death was determined using terminal deoxynucleotidyl transferase-mediated biotinylated UTP nick end labeling (TUNEL) (Roche Products, Welwyn Garden City, UK) staining with $\mathrm{DAB}$ as the chromogen, and sections were counterstained with $4^{\prime}, 6^{\prime}$-diamidino-2-phenylindole. Sections were analyzed and photographed using confocal microscopy. Cell death was calculated as the number of TUNEL-positive cells per total number of cells counted in matched areas of five sections at $40 \times$ magnification.

RNA isolation. Mice were killed by cervical dislocation and dissected as described previously (Sandberg et al., 2000). Tissues were dissected and snap frozen on dry ice. Samples were stored at $-80^{\circ} \mathrm{C}$ until the RNA was isolated using Trizol according to the instructions of the manufacturer.

Bilateral common carotid artery occlusion. Mice were anesthetized and kept in the supine position. Body temperature was maintained by a blanket that was servo controlled at $37 \pm 1^{\circ} \mathrm{C}$ by a rectal temperature probe during the surgery and $1 \mathrm{~h}$ after reperfusion. Animals monitored for longer time periods showed no variations. The common carotid arteries were occluded bilaterally for $75 \mathrm{~min}$. Arterial blood gases and blood pressure were measured before and during ischemia through the right femoral artery. We monitored relative cerebral blood flow by laser Doppler flowmetry, as we described previously (Wang et al., 1998), and found no significant difference between HIF- $1 \alpha^{\Delta / \Delta}$ and HIF- $1 \alpha^{\mathrm{F} / \mathrm{F}}$ mice. Seventy-two hours after the procedure, mice were perfused with $4 \%$ paraformaldehyde. The brains were dissected and submerged in $4 \%$ paraformaldehyde overnight at $4^{\circ} \mathrm{C}$. Coronal sections were cut through the forebrain at $50 \mu \mathrm{m}$ intervals with a vibratome. The sections were dried at room temperature for $2 \mathrm{~h}$ and stained using acid fusin and cresyl violet as described previously (Fujii et al., 1997). The grading scale for neuronal damage was as described previously (Fujii et al., 1997): 0, normal; 1, a few (30\%) neurons damaged; 2, many neurons (30-70\%) damaged; and 3, majority of neurons (70\%) damaged. All experiments were performed with the investigator blinded as to the genotype of the animal.

Microarray analysis. cDNA arrays were used to identify the time of maximum overall gene expression in response to a hypoxic insult. Based on our Northern blotting results, HIF- $1 \alpha$ induction is maximal $1 \mathrm{~h}$ after exposure. A total of six mice were subjected to $4.5,16$, or 36 h of hypoxia. Arrays containing $\sim 8000$ different mouse cDNAs were spotted in duplicate at The Salk Institute microarray facility (Caceres et al., 2003). For hybridization to the arrays, $3 \mu \mathrm{g}$ of cRNA was labeled with cyanine 5 (Cy5) or Cy3 by an aminoallyl indirect labeling procedure. One comparison of HIF-1 $\alpha^{F / F}$ over HIF-1 $\alpha^{\Delta / \Delta}$ was done for each time point. After scanning the hybridized slides, background-subtracted data of all spots in the Cy5 and Cy 3 channels were scaled to a common value in each slide, and only spots with a signal greater than background in at least $25 \%$ of the hybridizations were considered further. Expression differences between HIF- $1 \alpha^{\Delta / \Delta}$ and HIF- $1 \alpha^{F / F}$ were considered significant if the average relative change between the two species was $>1.8$-fold.

Having established that the maximal genomic response occurred at $4.5 \mathrm{~h}$ of hypoxia, we next conducted an experiment to define the genes regulated by HIF- $1 \alpha$ in response to hypoxia. Total RNA was isolated and prepared as described above. Hippocampi from a total of 12 animals were used to generate expression profiles (triplicate sets of age- and sexmatched animals): no hypoxia HIF- $1 \alpha^{\Delta / \Delta}[n=3$ animals; two males (M) at 30 and 34 weeks, one female (F) at 9 weeks], no hypoxia HIF-1 $\alpha^{F / F}$ ( $n=3$ animals; two $\mathrm{M}$ at 30 and 35 weeks, one $\mathrm{F}$ at 9 weeks), $4.5 \mathrm{~h}$ hypoxia HIF- $1 \alpha^{\Delta / \Delta}$ ( $n=3$ animals; three $\mathrm{F}$ at 9 weeks), and 4.5 h hypoxia HIF$1 \alpha^{F / F}$ ( $n=3$ animals; two $\mathrm{F}$ at 9 weeks, one $\mathrm{F}$ at 10 weeks). No samples were pooled. Labeling of samples, hybridization, and scanning were performed as described previously (Wodicka et al., 1997; Sandberg et al., 2000) using the Affymetrix (Santa Clara, CA) Genechip MG_U74Av2 microarray that represents 12,422 probes sets corresponding to $\sim 12,000$ genes and expressed sequence tags (Affymetrix). After scanning the chips with the Affymetrix GeneArray Scanner, the ".cel" files were analyzed using algorithms developed by our laboratory in a Teradata (NCR, Dayton, OH) analytical relational database using the Teragenomics software tool (Information Management Consultants, McLean, VA) (Zapala et al., 2002; Caceres et al., 2003) and the freeware tool Bullfrog. Samples were scaled to a target intensity of 200, which has been shown to correspond to approximately three to five transcripts per cell (Wodicka et al., 1997).

To identify specific sets of differentially expressed genes, files were compared using Teragenomics. Pairwise comparisons were made for the following groups: (1) replicates in each group; (2) no hypoxia $H I F-1 \alpha^{F / F}$ versus no hypoxia $H I F-1 \alpha^{\Delta / \Delta}$; (3) 4.5 h hypoxia $H I F-1 \alpha^{F / F}$ versus $4.5 \mathrm{~h}$ hypoxia $H I F-1 \alpha^{\Delta / \Delta}$; (4) no hypoxia HIF-1 $\alpha^{F / F}$ versus $4.5 \mathrm{~h}$ hypoxia HIF$1 \alpha^{F / F}$; and (5) no hypoxia HIF- $1 \alpha^{\Delta / \Delta}$ versus $4.5 \mathrm{~h}$ hypoxia $H I F-1 \alpha^{\Delta / \Delta}$. 
Comparisons were then exported to Bullfrog version 7 (Lockhart and Lockhart, San Diego, CA) (Zapala et al., 2002) for additional analysis. The criteria used to establish experimental reproducibility between replicates were a fold change of $\geq 1.5$; a difference call of increase, marginal increase, decrease, or marginal decrease; and a signal change $>30$ in three of three comparisons. Briefly, the difference call is designed to provide a qualitative determination of whether there is an expression level difference between two measurements. The difference call is based on differences in the observed hybridization patterns (scaled intensities) between two measurements for all of the probes in a probe set. The algorithm uses the collection of matched differences between the appropriately scaled perfect match (PM) - mismatch $(\mathrm{MM})$ values (experiment 1 compared with experiment 2 ) and is again based on the $p$ value (paired, two-tailed) calculated using the nonparametric Wilcoxon's signed rank test (relative), as well as the "increase fraction" [the fraction of $(\mathrm{PM}-\mathrm{MM})_{1}-(\mathrm{PM}-\mathrm{MM})_{2}$ values that are greater than zero]. In particular, the algorithm uses the collection of relative differences for each probe pair in the probe set: $\left\{\left[(\mathrm{PM}-\mathrm{MM})_{1}-(\mathrm{PM}-\mathrm{MM})_{2}\right] /[(\mathrm{PM}-\right.$ $\left.\left.\mathrm{MM})_{1}+(\mathrm{PM}-\mathrm{MM})_{2}\right]\right\}$. Absolute values are used in the denominator because PM - MM values can be negative, and a minimum denominator setting is used to avoid dividing by zero or a number that is too small relative to the noise. In addition, to make the difference call even more conservative (and to minimize the effects of small interchip scaling imperfections), the difference $p$ value for each probe set is calculated multiple times under the assumption that the scaling factor could be off by as much as a factor of 1.15 in either direction. After this calculation, the largest or most conservative $p$ value is used to make the difference call (and is the $p$ value reported for other uses). The difference call thresholds were set to maximize sensitivity to small expression differences while keeping the false-positive rate to a minimum and were based on an analysis of a large amount of experimental data. Genes were considered to be differentially expressed between two samples and called increased if $p<0.01$ and the increased fraction $\geq 0.7$, called marginally increased if $p<0.0316$ and the increased fraction $\geq 0.8$, called decreased if $p<0.01$ and the increased fraction $\leq 0.3$, and called marginally decreased if $p<0.0316$ and the increased fraction $\leq 0.2$ (access to the full MIAMEcompliant data set is available at http://www.teragenomics.com/public/ helton01.asp) (see supplemental MIAME checklist, available at www.jneurosci.org as supplemental material).

Replicate pairwise comparisons were analyzed to determine the falsepositive rate. The false-positive rate for the analysis of baseline changes is described in Results. The false-positive rate for the analysis of the hypoxic response was determined using the replicate comparisons and asking that the gene was consistently differentially expressed (using the statistical and fold change criteria described above) in $67 \%$ of the comparisons ( 8 of 12). No genes were identified that met this criteria $(0 \%$ false-positive rate). Similar analysis was then applied to comparisons between the hypoxia and no hypoxia animals to find the genes that were consistently changed by hypoxia in at least $67 \%$ of the pairwise comparisons (six of nine for each genotype). The "Venn" function in Bullfrog was then used to identify genes that were unique or common to the response based on genotype.

Ingenuity pathways analysis. The biological network data were generated through the use of Ingenuity Pathways Analysis, a web-delivered application that enables biologists to discover, visualize, and explore therapeutically relevant networks significant to their experimental results, such as gene-expression array data sets. A data set of the genes containing Affymetrix probe set gene identifiers that are differentially expressed in both the wild-type and mutant hippocampus after hypoxia was uploaded to Ingenuity as a tab-delimited text file. Each gene identifier was mapped to its corresponding gene object in the Ingenuity Pathways Knowledge Base. These genes, called Focus Genes, were then used as the starting point for generating biological networks. To start building networks, the application queried the Ingenuity Pathways Knowledge Base for interactions between Focus Genes and all other gene objects stored in the knowledge base and generated a set of networks with a network size of 20 genes/proteins. Ingenuity Pathways Analysis then computed a score for each network according to the fit of the user's set of significant genes. The score is derived from a $p$ value and indicates the likelihood of the Focus Genes in a network being found together because of random chance. A score of 2 indicates that there is a 1 in 100 chance that the Focus Genes are together in a network because of random chance. Therefore, scores of $\geq 2$ have at least a $99 \%$ confidence of not being generated by random chance alone. Biological functions are then calculated and assigned to each network by using the findings that have been extracted from the scientific literature and stored in the Ingenuity Pathways Knowledge Base. The biological functions assigned to each network are ranked according to the significance of that biological function to the network. A Fisher's exact test is used to calculate a $p$ value determining the probability that the biological function assigned to that network is explained by chance alone.

Real time quantitative reverse transcription-PCR. Standard protocols were used for the generation of cDNA from RNA after eliminating genomic DNA contamination using DNase (Ambion, Austin, TX). Oligonucleotide primers were designed using Primer Express software version 1.5 (Applied Biosystems, Foster City, CA). SYBR Green PCR Master Mix (Applied Biosystems) was used for the reverse transcription (RT)PCR, which were then run on the Applied Biosystems Prism 7700 Sequence Detection System. All RT-PCR data analyses were normalized to peptidylprolyl isomerase B (cyclophilin) levels as an internal control, and statistical analysis was done using a paired, two-tailed Student's $t$ test.

\section{Results}

Haploinsufficiency for HIF-1 $\alpha$ results in increased cell survival in response to hypoxia

Neurons in the CA1 region of the hippocampus typically show the greatest susceptibility to hypoxic damage (Cervos-Navarro and Diemer, 1991). To determine the threshold for hypoxic damage and induction of HIF- $1 \alpha$ expression, normal mice were exposed to various levels of hypoxia in a hypoxic chamber. Northern blot analysis performed on RNA isolated from mouse brain after a $1 \mathrm{~h}$ exposure to $7 \% \mathrm{O}_{2}$ revealed maximal induction of HIF-1 $\alpha$ (data not shown). Immunohistochemistry for glial acid fibrillary protein and TUNEL staining plus morphological analysis performed at $48 \mathrm{~h}$ after hypoxia confirmed that gliosis and cell death were induced in the CA1 region of the hippocampus.

To determine the role of HIF- $1 \alpha$ in neuronal survival during hypoxia, we initially exposed WT and heterozygous $\left(H I F-1 \alpha^{+/ N e o}\right)$ mice (all tissues haploinsufficient for HIF-1 $\alpha$ ) (Ryan et al., 2000) to

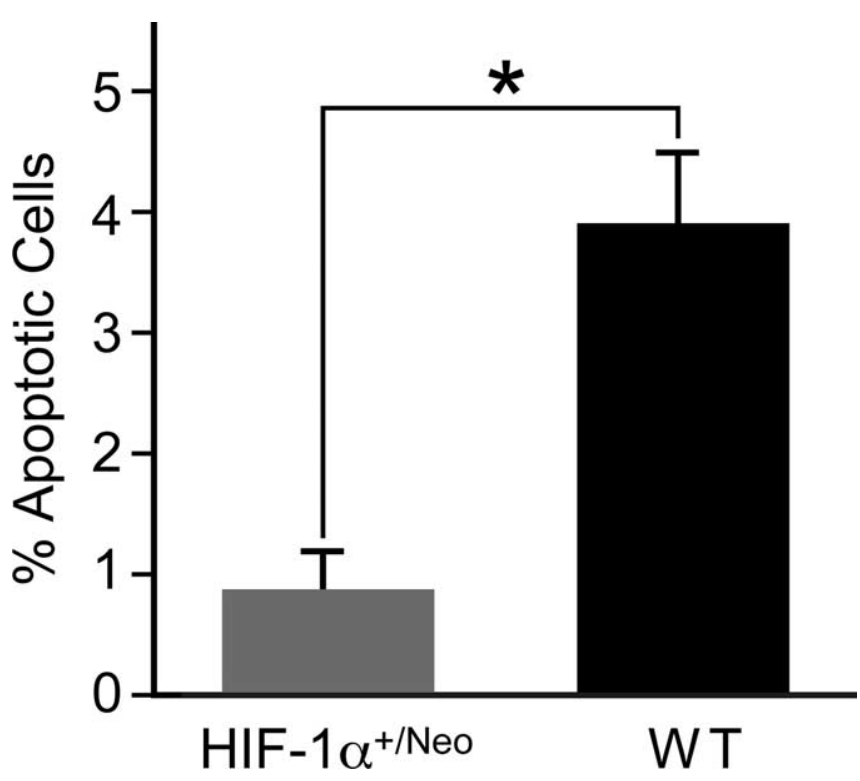

Figure 1. Quantitative results based on cell counting are graphed as the percentage of apoptotic cells in the heterozygous HIF- $1 \alpha^{+/ \text {Neo }}(n=5)$ and WT $(n=9)$ CA1 region of the hippocampus. The abscissa indicates the genotype. The ordinate indicates the percentage of TUNEL-positive cells. Statistical significance was calculated using a Student's $t$ test $\left({ }^{*} p<\right.$ 0.001). Error bars indicate SD. 

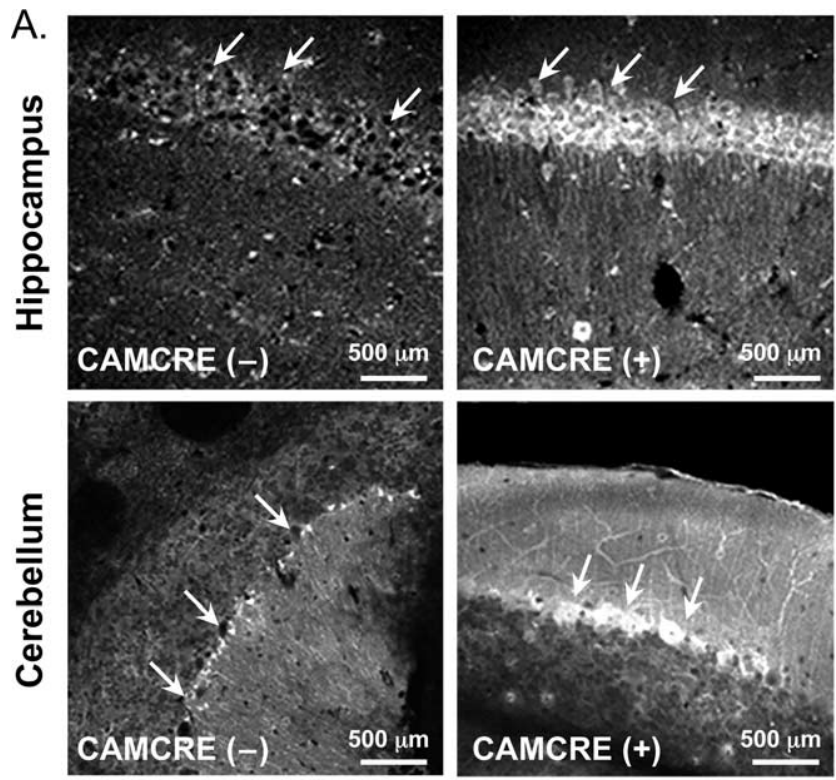

B.

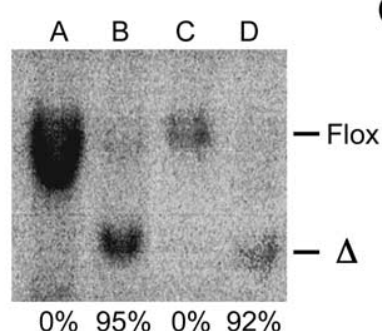

C.

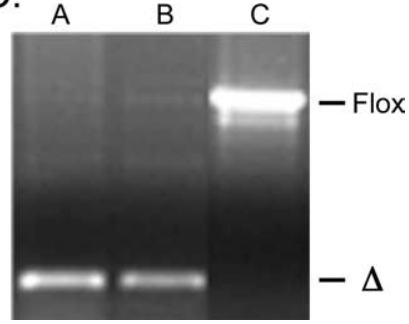

Figure 2. Efficiency of CRE recombinase-mediated deletion. $\boldsymbol{A}$, Immunohistochemistry for CRE shows that neurons in the hippocampus (top right panel, white arrows) and cerebellar Purkinje cells (bottom right panel, white arrows) express CRE in the CAMCRE transgenic mouse $\left(C A M C R E^{+}\right)$. In contrast, no staining is detected in the control $C R E^{-}$mice (CAMCRE ${ }^{-}$, top and bottom left panels). Scale bars, $500 \mu \mathrm{m}$. B, Southern blot analysis performed on DNA isolated from the cortex (lane A) and hippocampus (lane C) of an HIF- $1 \alpha^{F / F}$ genotype mouse and from the cortex (lane B) and hippocampus (lane D) of an HIF- $1 \alpha^{\Delta / \Delta}$ genotype mouse. The line labeled Flox indicates the undeleted $2.2 \mathrm{~kb}$ HIF-1 $\alpha$ flox allele. The line labeled $\Delta$ indicates the $1.2 \mathrm{~kb} \mathrm{HIF-1} \alpha$-deleted allele. Percentage of deletion is represented below the corresponding lanes. $C, P C R$ fragments from DNA isolated from the cortex (lane A) and hippocampus (lane B) of an HIF-1 $\alpha^{\Delta / \Delta}$ genotype mouse and from the cortex (lane C) of an HIF-1 $\alpha^{\mathrm{F} / \mathrm{F}}$ mouse. The line labeled Flox indicates the undeleted $1 \mathrm{~kb}$ HIF- $1 \alpha$ allele. The line labeled $\Delta$ indicates the 300 bp-deleted allele.

$7 \% \mathrm{O}_{2}$ for $1 \mathrm{~h}$, and cell death was quantified $48 \mathrm{~h}$ later using the TUNEL assay (Roche Products). Surprisingly, HIF-1 $\alpha^{+/ \text {Neo }}$ mice manifested a significant decrease in cell death in the CA1 region of the hippocampus compared with the WT mice $\left({ }^{*} p<0.0001\right)$ (Fig. 1). The finding that systemic haploinsufficiency for HIF-1 $\alpha$ leads to neuroprotection could be explained by several potential mechanisms, and the possibility remained that HIF- $1 \alpha$ deletion outside of the brain had an effect on the phenotype. To further understand these intriguing but preliminary findings, we generated mice with a deletion of HIF-1 $\alpha$ selectively in the brain and refined our methods to specifically address the role of HIF- $1 \alpha$ in the adult brain in a model of acute hypoxia attributable to vascular occlusion.

\section{Generation of mice with brain predominant deletion of $\mathrm{HIF}-1 \mathrm{\alpha}$}

To fully understand the function of HIF- $1 \alpha$ in the CNS in response to hypoxia, complete deletion in the brain would be optimal. Because complete deletion of both alleles of HIF-1 $\alpha$ leads
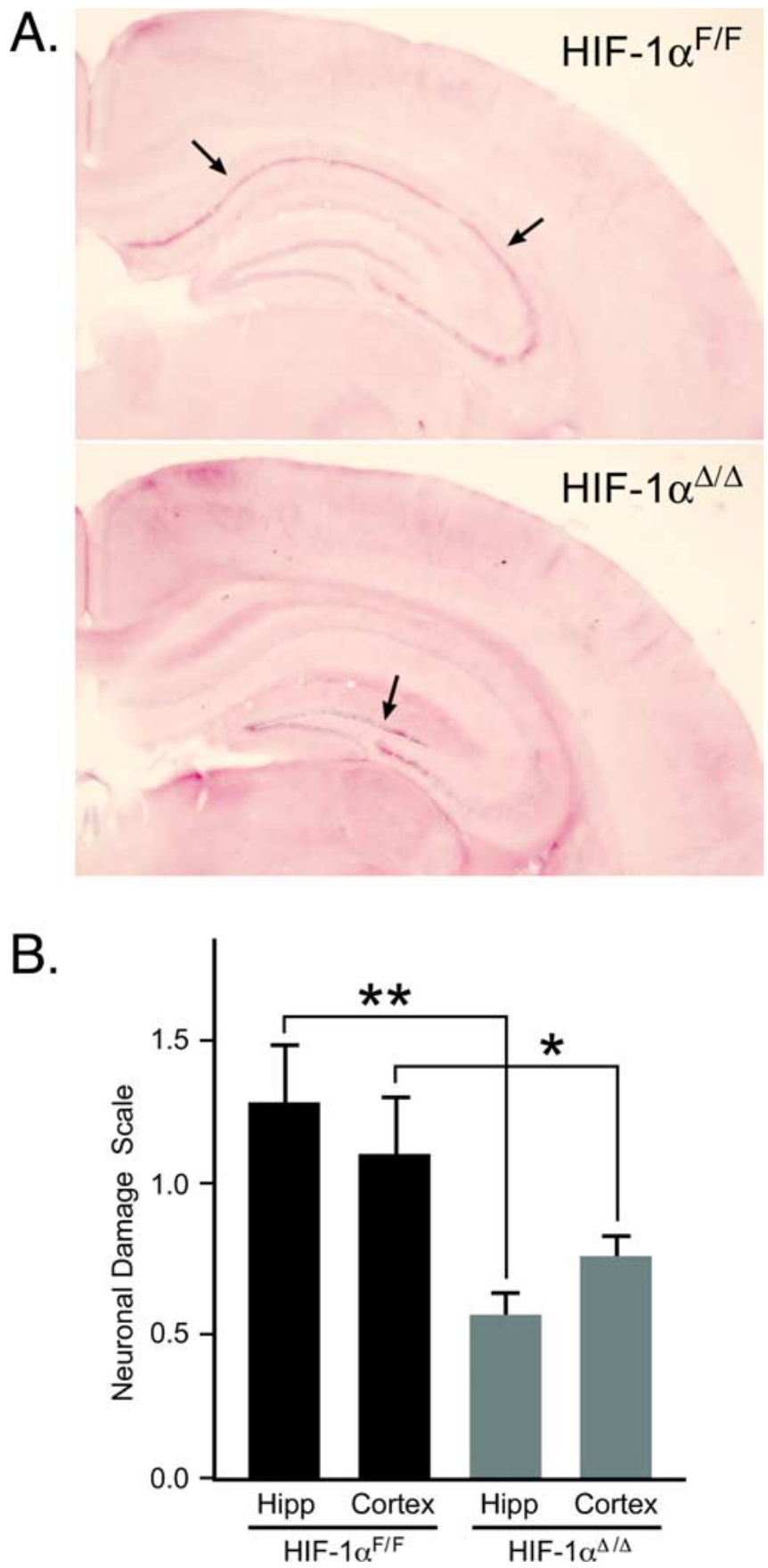

Figure 3. Absence of HIF-1 $\alpha$ is protective during global ischemia. $A$, A representation of acid fusin- and cresyl violet- stained sections from $H I F-1 \alpha^{F / F}$ (wild-type) and $H I F-1 \alpha^{\Delta / \Delta}$ (mutant) hippocampus shows a substantial decrease in neuronal damage in the HIF- $1 \alpha^{\Delta / \Delta}$ mice. Arrows indicate regions of neuronal damage. $\boldsymbol{B}$, Mean neuronal damage in the cortex and hippocampus (Hipp) in HIF- $1 \alpha^{\mathrm{F} / \mathrm{F}}$ and HIF- $1 \alpha^{\Delta / \Delta}$ mice after a $75 \mathrm{~min} \mathrm{BCCA0}$ and $3 \mathrm{~d}$ reperfusion is shown. Ischemic neuronal damage was graded on a four-point scale basis. Neuronal damage in the cortex and hippocampus was significantly greater in HIF-1 $\alpha^{F / F}(n=6)$ versus HIF$1 \alpha^{\Delta / \Delta}(n=13)$ mice. ${ }^{*} p<0.05 ; * * p<0.005$. Sections were viewed at $2 \times$ magnification. The data were compared using a Student's $t$ test.

to embryonic lethality (Ryan et al., 1998), we generated mice with a brain predominant deletion of HIF-1 $\alpha\left(H I F-1 \alpha^{\Delta / \Delta}\right)$. We generated transgenic mice expressing CAMCRE that promotes brain-specific deletion of loxP-flanked (floxed) sequences (Dragatsis and Zeitlin, 2000). This CRE transgenic animal promotes deletion of loxP-flanked sequences no earlier than embryonic day 18.5 and shows the highest recombination after postnatal day 5 in 
Table 1. Genes increased in HIF-1 $\alpha^{\Delta / \Delta}$ versus $H I F-1 \alpha^{F / F}$ at baseline

\begin{tabular}{lllll}
\hline \multirow{2}{*}{ Probe set } & Gene title & $\begin{array}{l}\text { Avg ratio (FC) } \\
\text { (MUT:WT) }\end{array}$ & $\begin{array}{l}\text { Avg chg } p \text { value } \\
\text { (MUT:WT) }\end{array}$ & Gene symbol \\
\hline 100012_at & lysosomal-associated protein transmembrane 5 & 1.4 & $6.46 \mathrm{E}-02$ & Laptm5 \\
102704_at & aquaporin 4 & 1.5 & $1.07 \mathrm{E}-02$ & Aqp4 \\
103994_at & eukaryotic translation initiation factor 2C, 2 & 1.7 & $4.17 \mathrm{E}-02$ & Eif2c2 \\
160163_at & N-terminal Asn amidase & 1.5 & $4.90 \mathrm{E}-02$ & Nitan1 \\
93965_r_at & DEAD (Asp-Glu-Ala-Asp) box polypeptide 6 & 1.9 & $1.66 \mathrm{E}-02$ & Ddx6 \\
96215_f_at & Mus musculus, clone IMAGE:3983821, mRNA, partial cds & 2.3 & $2.51 \mathrm{E}-02$ & \\
99009_at & nicotinamide nucleotide transhydrogenase & 1.8 & $3.16 \mathrm{E}-02$ & Nnt
\end{tabular}

MUT indicates HIF- $1 \alpha^{\Delta / \Delta}$; WT indicates HIF-1 $\alpha^{F / F}$; Avg ratio (FC) indicates the average fold change; Avg chg $p$ value is the $p$ value (paired, two-tailed) calculated using the nonparametric Wilcoxon's signed rank test (relative).

mature neurons and astrocytes (Dragatsis and Zeitlin, 2000). The CAMCRE mice were crossed to mice carrying HIF-1 $\alpha$ alleles flanked by loxP sites (HIF-1 $\left.\alpha^{F / F}\right)$ (Ryan et al., 1998). Mice homozygous for the HIF-1 $\alpha$ flox allele and carrying the CAMCRE transgene were born at the expected ratio without any evidence of developmental abnormalities (data not shown), suggesting that deletion of HIF- $1 \alpha$ in mature cells of the brain is not disadvantageous. After monitoring the colony over time, we noted a rare but not statistically significant incidence of hydrocephalus in the colony $\left(H I F-1 \alpha^{F / F}, n=0\right.$ of 78 ; HIF- $1 \alpha^{\Delta / \Delta}, n=5$ of $\left.160 ; p>0.12\right)$. Therefore, we found no evidence that using the CAMCRE mice to delete $H I F-1 \alpha$ in mature cells of the nervous system results in abnormalities similar to that found with deletion during development (Ryan et al., 1998; Tomita et al., 2003).

\section{HIF-1 $\alpha$ excision is complete in cortex and hippocampus}

To confirm that CRE was expressed in the target population of cells, immunohistochemistry using a CRE-specific antibody was performed. As shown, CRE was detected in neurons in the hippocampus (Fig. 2A, arrows) and cerebellar Purkinje cells (Fig. $2 A$, arrows). To quantify the extent of deletion, Southern blot analysis was performed on two HIF-1 $\alpha^{\Delta / \Delta}$ mice (Fig. $2 B$ ). Southern blot analysis showed that deletion of both HIF-1 $\alpha$ flox alleles was virtually complete in cortex and hippocampus (Fig. $2 \mathrm{~B}$, lane B, 95\%, lane D, 92\%). PCR performed on multiple independent samples were consistent with the Southern blot analysis (Fig. $2 \mathrm{C}$ and data not shown).

\section{Neuroprotection from global ischemia by HIF-1 $\alpha$ deletion}

The bilateral common carotid artery occlusion (BCCAo) stroke model was used to induce ischemia, because this model leads to substantial and consistent cell death in the hippocampus and cortex. Cell death was assessed at $72 \mathrm{~h}$ after occlusion, a time at which we see maximal cell death in this model (Fujii et al., 1997). As shown (Fig. $3 A, B$ ), neuronal damage was statistically greater in the HIF-1 $\alpha^{F / F}(n=6)$ compared with HIF-1 $\alpha^{\Delta / \Delta}(n=13)$ mice after a 75 min BCCAo, followed by $3 \mathrm{~d}$ of reperfusion. The neuronal damage scores (see Materials and Methods) in cortex were HIF- $1 \alpha^{F / F}, 1.11 \pm 0.19$ versus HIF- $1 \alpha^{\Delta / \Delta}, 0.74 \pm 0.08\left({ }^{*} p<\right.$ $0.05)$ and in hippocampus were $H I F-1 \alpha^{F / F}, 1.28 \pm 0.21$ versus $H I F-1 \alpha^{\Delta / \Delta}, 0.58 \pm 0.08\left({ }^{*} p<0.005\right)$. Arterial blood gases $[\mathrm{pH}$, $7.36 \pm 0.02$ vs $7.32 \pm 0.03 ; \mathrm{PaCO}_{2}, 23.19 \pm 2.8$ vs $30.72 \pm 2.4$ mmHg; $\mathrm{PaO}_{2}, 218.9 \pm 13.8$ vs $\left.210.3 \pm 11.5 \mathrm{mmHg}\right] ; \mathrm{Na}^{+}$, $149.5 \pm 0.85$ versus $150.3 \pm 0.49 \mathrm{mmol} / \mathrm{l} ; \mathrm{Ca}^{2+}, 1.04 \pm 0.02$ versus $1.06 \pm 0.03 \mathrm{mmol} / \mathrm{l}$; glucose levels, $139.3 \pm 15.06$ versus $140.8 \pm 11.41 \mathrm{mg} / \mathrm{dl}$; mean blood pressure, $146.6 \pm 9.48$ versus $132.3 \pm 5.84 \mathrm{mmHg}$; and core temperature were not different between the two groups. The finding of decreased cell death in this more vigorous model was consistent with the preliminary data using the hypoxia chamber. Together, these data confirm that deple- tion of HIF- $1 \alpha$ is actually neuroprotective after an acute hypoxic-ischemic insult to the brain.

\section{HIF-1 $\alpha$ deletion in the hippocampus does not significantly affect baseline gene expression}

HIF- $1 \alpha$ is believed to be a key component in the cellular response to hypoxia and ischemia. How then could loss of HIF- $1 \alpha$ in acute hypoxic insult result in neuroprotection? To answer this question, we first used transcriptional profiling to assess whether there was a difference in gene expression at baseline that might explain the neuroprotection. We measured the transcriptional profile of mutant HIF-1 $\alpha^{\Delta / \Delta}$ and WT HIF-1 $\alpha^{F / F}$ mouse hippocampi in the absence of any stressor (i.e., no hypoxia/ischemia). To determine the gene-expression changes in HIF-1 $\alpha^{\Delta / \Delta}$ hippocampus compared with $H I F-1 \alpha^{F / F}$ hippocampus at baseline, we performed several analyses (see Materials and Methods). Initially, we made comparisons between animals of the same genotype at baseline to assess the performance of replicates. Because these comparisons were between replicates within a group, any genes returned as significantly different would be considered false positives. On average, using very stringent criteria, no genes (of 12,422 ) were consistently or statistically significantly different between replicates when all pairwise comparisons were considered. However, using these criteria, there were no changes detected between the HIF-1 $\alpha^{\Delta / \Delta}$ and HIF-1 $\alpha^{F / F}$ either. Using less stringent criteria (see Materials and Methods), 14 genes were identified that were statistically significantly different in the majority of baseline replicate comparisons (false-positive rate of $0.11 \%)$. We then applied similar criteria to define genes that were differentially expressed in the HIF-1 $\alpha^{F / F}$ versus $H I F-1 \alpha^{\Delta / \Delta}$ mice hippocampus at baseline (before hypoxia; see Materials and Methods). Consistent with the lack of obvious phenotype in the $H I F-1 \alpha^{\Delta / \Delta}$ mice, only seven genes were differentially expressed between the HIF-1 $\alpha^{F / F}$ and HIF-1 $\alpha^{\Delta / \Delta}$ hippocampi in a pattern that was consistent between genotypes (Table 1). Interestingly, the gene Aquaporin 4, encoding a bidirectional water channel in the CNS implicated to play an important role in brain water homeostasis (Papadopoulos and Verkman, 2005), was upregulated in the HIF-1 $\alpha^{\Delta / \Delta}$ mice. It would be interesting to speculate whether Aquaporin 4 could be responsible for the rare occurrences of hydrocephalus seen in the HIF-1 $\alpha^{\Delta / \Delta}$ mice. However, based on the false discovery rate, these genes may be false positives, and none of them readily explained the neuroprotection. Therefore, we feel it is unlikely that the absence of HIF- $1 \alpha$ at baseline resulted in significant changes in gene expression (e.g., similar to hibernation or preconditioning) that could account for the phenotype of neuroprotection.

\section{Functional redundancy and downregulation of proapoptotic genes in $\mathrm{HIF}-1 \alpha^{\Delta / \Delta}$ mice}

In contrast to the lack of a phenotype found at baseline, the $H I F-1 \alpha^{\Delta / \Delta}$ mice showed a decrease in hypoxia-induced apoptosis of cortical neurons. During hypoxic stress, HIF- $1 \alpha$ is thought to act through the induction of multiple genes involved in metabolic adaptation and tissue survival. Therefore, we wanted to determine how the transcriptional response in the brain during hypoxia differed between $H I F-1 \alpha^{\Delta / \Delta}$ and $H I F-1 \alpha^{F / F}$ mice. In addition, we were interested in identifying genes that may mediate the HIF- $1 \alpha$-dependent induction of cell death as well as defining 

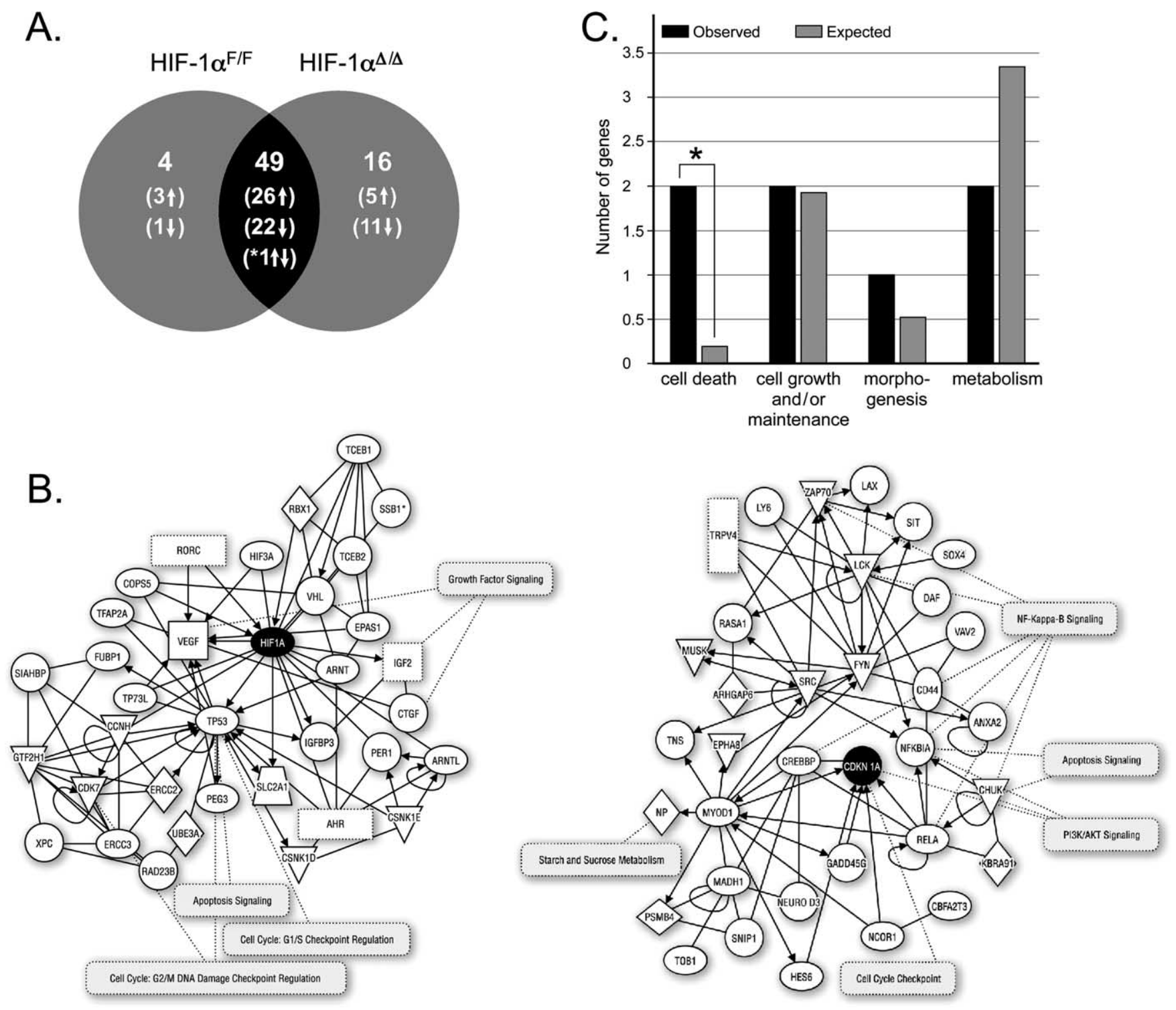

Figure 4. HIF-1 $\alpha$ is not required for the classic transcriptional response to hypoxia. Venn diagram $(A)$ of the number of differentially expressed genes and the direction of change in response to hypoxia in the hippocampus of HIF- $1 \alpha^{F / F}$ animals, HIF-1 $\alpha^{\Delta / \Delta}$ animals, or both. The differentially expressed genes were firstidentified for each of the genotypes; then the gene lists from each group were analyzed for unique and overlapping gene expression (see Materials and Methods). Of the four genes changed uniquely in the $H I F-1 \alpha^{F / F}$ hippocampus after hypoxia, three genes were increased and one was decreased (Table 1). Of the 16 genes unique to the HIF- $1 \alpha^{\Delta / \Delta}$ hippocampus after hypoxia, five increased and 11 decreased (Table 4). 0 f the 49 genes in common to both genotypes after hypoxia, 27 increased and 22 decreased (Table 2). One gene was oppositely expressed, showing increased expression in the HIF- $1 \alpha^{\Delta / \Delta}$ hippocampus and decreased expression in the HIF- $1 \alpha^{\mathrm{F} / \mathrm{F}}$ hippocampus after hypoxia (Table 5). $\uparrow$ or $\downarrow$ indicates direction change in response to hypoxia; $\left({ }^{*} \uparrow \downarrow\right.$ ) indicates that this gene is expressed in opposite directions in HIF- $1 \alpha^{F / F}(\downarrow)$ and $H I F-1 \alpha^{\Delta / \Delta}(\uparrow) . B$, Ingenuity pathway analyses are shown for the genes induced by hypoxia in common to both mutant and normal animals. Two networks were identified and are displayed graphically as nodes (genes/gene products) and edges (the biological relationships between the nodes). Of the 49 genes in common to both genotypes, 19 mapped to two specific networks and one connected to HIF- $1 \alpha\left({ }^{*} p<1.0 \times 10^{-8}\right)$ and CDKN1A (p21) $\left({ }^{*} p<1.0 \times 10^{-19}\right)$.C, Quantitative results are graphed as the biological process using the Gene Ontology Tree Machine program. The abscissa indicates the pathways interrogated using the program, and only cell death showed a significance of enrichment $\left({ }^{*} p<0.02\right)$. The ordinate indicates the number of genes observed in each category compared with the number of genes expected.

potential genes whose regulation in the absence of HIF- $1 \alpha$ may account for the neuroprotection phenotype observed. We performed an initial microarray experiment to identify the time of the maximal transcriptional response in the hippocampus after hypoxia. The maximal response was observed $4.5 \mathrm{~h}$ after induction of hypoxia at $7 \% \mathrm{O}_{2}$ and diminished dramatically thereafter (see Materials and Methods) (data not shown). Based on these data, we then performed an entirely independent experiment on normal and mutant mice using Affymetrix oligonucleotide arrays to define the genes differentially regulated by HIF- $1 \alpha$ in the hippocampus after exposure to hypoxia for $4.5 \mathrm{~h}$ (for details, see Materials and Methods).
Surprisingly, HIF- $1 \alpha$ is not required for the classically defined transcriptional response after hypoxia (Fig. 4). A total of 69 genes were identified that were induced by hypoxia in either the HIF$1 \alpha^{\Delta / \Delta}$ or HIF-1 $\alpha^{F / F}$ hippocampus or in mice of both genotypes (Fig. 4A). Of these 69 genes, 49 were changed in both the HIF$1 \alpha^{\mathrm{F} / \mathrm{F}}$ and the HIF-1 $\alpha^{\Delta / \Delta}$ mice in the same direction and to a similar degree (Fig. 4A, Table 2). Only four genes were induced/ repressed uniquely in the mice with intact HIF function (Fig. $4 \mathrm{~A}$, Table 3). Sixteen genes were changed only in the mice lacking $H I F-1 \alpha$ (Fig. 4A, Table 4). One gene, RIKEN cDNA accession number $1110015 \mathrm{E} 22$, was decreased in the HIF-1 $\alpha^{F / F}$ mice and increased in the HIF-1 $\alpha^{\Delta / \Delta}$ mice (Fig. $4 A$, Table 5). 
Table 2. Genes changed after hypoxia that are common to HIF-1 $\alpha^{\mathrm{F} / \mathrm{F}}$ and HIF-1 $\alpha^{\Delta / \Delta}$

\begin{tabular}{|c|c|c|c|c|}
\hline Probe set & Gene title & $\begin{array}{l}\text { Avg ratio (FC) } \\
\text { (WT:MUT) }\end{array}$ & $\begin{array}{l}\text { Avg chg } p \text { value } \\
\text { (WT:MUT) }\end{array}$ & Gene symbol \\
\hline 94881_at & cyclin-dependent kinase inhibitor 1A (p21) & $3.4: 3.8$ & $6.92 \mathrm{e}-3: 2.24 \mathrm{e}-3$ & Cdkn1a \\
\hline 103520_at & vascular endothelial growth factor A & $2.5: 2.0$ & $1.95 \mathrm{e}-2: 2.24 \mathrm{e}-2$ & Vegfa \\
\hline 100569_at & annexin $A 2$ & $2.4: 2.2$ & $9.12 e-3: 5.01 e-3$ & Anxa2 \\
\hline 98067_at & cyclin-dependent kinase inhibitor 1A (p21) & $2.4: 2.7$ & $4.27 e-3: 1.20 e-3$ & Cdkn1a \\
\hline 161817_f_at & RIKEN cDNA $4930422 J 18$ gene & $2.4: 2.2$ & $8.51 e-3: 4.47 \mathrm{e}-3$ & \\
\hline 161013_f_at & RIKEN CDNA 4930422J18 gene & $2.2: 2.4$ & $4.47 \mathrm{e}-2: 3.02 \mathrm{e}-2$ & 4930422J18Rik \\
\hline 93284_at & cold inducible RNA binding protein & 2.1:1.9 & $2.00 e-3: 1.62 e-3$ & Cirbp \\
\hline 101979_at & gadd $45 \gamma$ & $2.1: 2.6$ & $3.89 \mathrm{e}-3: 2.95 \mathrm{e}-3$ & Gadd45g \\
\hline 93619_at & period homolog 1 (Drosophila) & $2.0: 1.7$ & $9.33 e-3: 1.38 \mathrm{e}-2$ & Per1 \\
\hline 93294_at & connective tissue growth factor & $2.0: 1.6$ & $1.26 \mathrm{e}-2: 6.31 \mathrm{e}-2$ & $\operatorname{Ctg} f$ \\
\hline 101889_S_at & RAR-related orphan receptor $\alpha$ & $2.0: 1.3$ & $1.95 e-2: 9.33 e-2$ & Rora \\
\hline 101430_at & SRY-box containing gene 4 & $2.0: 1.9$ & 2.00e-2:1.02e-2 & Sox4 \\
\hline 93974_at & RIKEN CDNA $1300002 F 13$ gene & $1.9: 1.9$ & $3.09 e-3: 6.61 e-3$ & 1300002F13Rik \\
\hline 94288_at & histone 1, HIc & $1.9: 2.2$ & $9.77 e-3: 4.57 e-3$ & Hist1hlc \\
\hline 93527_at & basic transcription element binding protein 1 & $1.9: 1.5$ & $1.26 \mathrm{e}-2: 1.23 \mathrm{e}-2$ & Bteb1 \\
\hline 96841_at & proviral integration site 3 & $1.9: 1.9$ & $2.57 \mathrm{e}-3: 2.40 \mathrm{e}-3$ & Pim3 \\
\hline 96348_at & RIKEN CDNA 0610039C21 gene & $1.8: 2.0$ & $1.86 e-2: 4.17 e-3$ & 0610039C21Rik \\
\hline 160109_at & SRY-box containing gene 4 & $1.7: 1.9$ & $7.41 e-3: 8.32 e-3$ & Sox4 \\
\hline 104149_at & NF $\kappa$ inhibitor, $\alpha$ & $1.7: 1.9$ & $1.51 \mathrm{e}-2: 1.10 \mathrm{e}-2$ & Nfkbia \\
\hline 94297_at & FK506 binding protein 5 & 1.5:1.8 & $3.72 e-3: 1.51 e-3$ & Fkbp5 \\
\hline 96747_at & ras homolog gene family, member $U$ & $1.4: 1.9$ & $4.90 e-2: 9.77 e-4$ & Arhu \\
\hline 100133_at & Fyn proto-oncogene & $1.4: 1.6$ & 4.37e-2:1.70e-2 & Fyn \\
\hline 92202_g_at & Mus musculus similar to Zinc finger protein 145 & 1.4:1.6 & 3.31e-2:8.71e-4 & \\
\hline 102983_at & MAD homolog 1 (Drosophila) & 1.4:1.6 & $1.29 e-1: 8.71 e-3$ & Madh1 \\
\hline 95731_at & Mus musculus Sestrin 1 mRNA & $1.3: 1.6$ & $9.12 \mathrm{e}-3: 1.58 \mathrm{e}-3$ & Sesn1 \\
\hline 96103_f_at & RAD23b homolog (Saccharomyces cerevisiae) & 1.3:1.7 & $1.86 \mathrm{e}-1: 2.40 \mathrm{e}-2$ & $\operatorname{Rad23b}$ \\
\hline 96920_at & protease, serine, 11 (lgf binding) & 1.3:1.8 & $2.34 \mathrm{e}-2: 1.58 \mathrm{e}-3$ & Prss11 \\
\hline 94395_at & DNA segment, Chr 3, ERATO Doi 330 & $-1.2:-2.1$ & $5.50 \mathrm{e}-2: 4.90 \mathrm{e}-3$ & D3Ertd330e \\
\hline 92338_f_at & RIKEN CDNA $2310001 \mathrm{H} 12$ gene & $-1.3:-2.0$ & $1.41 e-1: 8.91 e-3$ & \\
\hline 95393_at & BTB (POZ) domain containing 3 & $-1.4:-2.0$ & $2.88 \mathrm{e}-2: 2.09 \mathrm{e}-3$ & Btbd3 \\
\hline 98761_i_at & zinc finger protein 97 & $-1.4:-2.4$ & $1.23 e-1: 1.66 e-3$ & Zfp97 \\
\hline 160857_at & ephrin B2 & $-1.5:-1.6$ & $2.19 e-2: 1.51 e-2$ & Efnb2 \\
\hline 160682_at & hypothetical protein $\mathrm{A} 730008 \mathrm{H} 23$ & $-1.5:-1.7$ & $1.45 \mathrm{e}-2: 2.04 \mathrm{e}-2$ & \\
\hline 95050_at & CHORD-containing, zinc-binding protein 1 & $-1.6:-1.9$ & $8.71 e-3: 2.00 e-3$ & Chordc1 \\
\hline 103081_at & bromodomain adjacent to zinc finger domain, $1 \mathrm{~B}$ & $-1.6:-1.5$ & $2.14 e-3: 8.91 e-3$ & Baz1b \\
\hline 99467_at & RAS p21 protein activator 1 & $-1.6:-1.9$ & $9.33 \mathrm{e}-3: 6.76 \mathrm{e}-3$ & Rasa1 \\
\hline 99070_at & conserved helix-loop-helix ubiquitous kinase & $-1.7:-2.0$ & $8.51 \mathrm{e}-3: 1.82 \mathrm{e}-3$ & Chuk \\
\hline 92243_at & RIKEN CDNA B930007L02 gene & $-1.7:-1.6$ & $3.63 e-3: 6.92 e-3$ & 1810017N16Rik \\
\hline 99532_at & transducer of ErbB-2.1 & $-1.7:-1.4$ & $2.63 \mathrm{e}-3: 2.24 \mathrm{e}-2$ & Tob1 \\
\hline 102318_at & sialyltransferase 8 ( $\alpha$-2, 8-sialytransferase) D & $-1.7:-2.3$ & $2.51 e-2: 3.16 e-3$ & Siat8d \\
\hline 98478_at & cyclin G2 & $-1.8:-1.7$ & $7.24 \mathrm{e}-4: 7.94 \mathrm{e}-3$ & Ccng2 \\
\hline 93274_at & CDC-like kinase & $-1.8:-2.4$ & $2.40 \mathrm{e}-3: 7.41 \mathrm{e}-4$ & Clk \\
\hline 93290_at & purine-nucleoside phosphorylase & $-1.8:-2.0$ & $3.72 \mathrm{e}-3: 3.55 \mathrm{e}-3$ & Pnp \\
\hline 93169_at & RIKEN cDNA 9630054P07 gene & $-1.8:-2.2$ & $6.17 \mathrm{e}-3: 1.86 \mathrm{e}-3$ & 9630054P07Rik \\
\hline 102397_at & core-binding factor, runt domain, $\alpha$ subunit 2 & $-1.8:-1.9$ & 3.80e-2:1.17e-2 & Cbfa2t3h \\
\hline 93104_at & B-cell translocation gene 1, anti-proliferative & $-2.0:-1.7$ & $1.32 \mathrm{e}-2: 4.07 \mathrm{e}-3$ & Btg1 \\
\hline 97848_at & RNA binding motif protein, $X$ chromosome & $-2.1:-3.7$ & $1.55 e-2: 1.55 e-3$ & Rbmx \\
\hline 97142_at & Mus musculus transcribed sequences & $-2.2:-2.8$ & 5.37e-2:3.72e-3 & \\
\hline 104694_at & similar to zinc finger protein 40 & $-2.3:-2.7$ & 4.17e-2:1.51e-2 & LOC224598 \\
\hline
\end{tabular}

WT indicates HIF- $1 \alpha^{F / F}$; MUT indicates HIF-1 $\alpha^{\Delta / \Delta}$; Avg ratio (FC) indicates the average fold change; Avg chg $p$ value is the $p$ value (paired, two-tailed) calculated using the nonparametric Wilcoxon's signed rank test (relative).

Table 3. Genes changed after hypoxia that are unique to $H I F-1 \alpha^{F / F}$

\begin{tabular}{llclc}
\hline Probe set & Gene title & Avg ratio (FC) WT & Avg chg $p$ value WT & Gene symbol \\
\hline 160613_at & lipocalin 7 & 1.9 & $2.24 \mathrm{E}-02$ & Lcn7 \\
102848_f_at & RIKEN CDNA 2610524H06 gene & 1.7 & $1.55 E-02$ & 2610524H06Rik \\
95033_at & jumonji domain containing 1 & 1.6 & $6.76 \mathrm{E}-03$ & Jmjd1 \\
92747_at & NK2 transcription factor related, locus 2 (Drosophila) & -1.9 & $1.41 \mathrm{E}-02$ & Nkx2-2 \\
\hline
\end{tabular}

WT indicates HIF-1 $\alpha^{F / F}$; Avg ratio (FC) indicates the average fold change; Avg chg $p$ value is the $p$ value (paired, two-tailed) calculated using the nonparametric Wilcoxon's signed rank test (relative).

To confirm that the basic gene-expression response pathway remains intact in the absence of HIF- $1 \alpha$, using Ingenuity Pathways Analysis, we asked to which biological networks the genes in common to both HIF-1 $\alpha^{F / F}$ and HIF-1 $\alpha^{\Delta / \Delta}$ mice belonged. Two specific networks were identified: one connected to HIF- $1 \alpha(p<$ $\left.1.0 \times 10^{-8}\right)$, the other to cyclin dependent kinase inhibitor $1 \mathrm{~A}$ $(\mathrm{CDKN1A})(\mathrm{p} 21)\left(p<1.0 \times 10^{-19}\right)($ Fig. $4 B)$. These results demonstrate that, in both the presence and absence of HIF-1 $\alpha$, 
Table 4. Genes changed after hypoxia that are unique to HIF-1 $\alpha^{\Delta / \Delta}$

\begin{tabular}{|c|c|c|c|c|}
\hline Probe set & Gene title & Avg ratio (FC) MUT & Avg chg $p$ value MUT & Gene symbol \\
\hline 103527_at & RIKEN CDNA A330108F03 gene & 2.2 & $7.94 \mathrm{E}-03$ & A330108F03Rik \\
\hline 160306_at & thyroid hormone responsive SPOT14 homolog (Rattus) & 1.9 & $1.26 \mathrm{E}-02$ & Thrsp \\
\hline 92958_at & forkhead box 03 & 1.9 & $1.15 \mathrm{E}-02$ & Fox03 \\
\hline 96735_at & START domain containing 10 & 1.8 & $5.50 \mathrm{E}-03$ & Stard10 \\
\hline 104320_at & pyridoxal (pyridoxine, vitamin B6) kinase & 1.5 & $6.31 \mathrm{E}-03$ & Pdxk \\
\hline 93240_f_at & UPF3 regulator of nonsense transcripts homolog B (yeast) & -1.5 & $1.66 \mathrm{E}-02$ & Upf3b \\
\hline 102781_at & cyclin L2 & -1.6 & $1.05 \mathrm{E}-02$ & Ccnl2 \\
\hline 160696_at & cytotoxic granule-associated RNA binding protein 1 & -1.6 & $6.61 \mathrm{E}-03$ & Tia1 \\
\hline 99947_at & Tial1 cytotoxic granule-associated RNA binding protein-like 1 & -1.7 & $3.09 \mathrm{E}-02$ & Tial1 \\
\hline 96302_at & splicing factor, arginine/serine-rich 7 & -1.7 & $1.12 \mathrm{E}-02$ & Sfrs7 \\
\hline 102645_at & early endosome antigen 1 & -1.8 & $1.95 \mathrm{E}-02$ & Eea1 \\
\hline 93471_at & solute carrier family 4, sodium bicarb cotransporter, member 7 & -1.9 & $6.03 \mathrm{E}-03$ & Slc4a7 \\
\hline 94192_at & RIKEN cDNA 1110035014 gene & -2.0 & $1.86 \mathrm{E}-02$ & 1110035014Rik \\
\hline 160979_at & TRAF-binding protein & -2.1 & $1.20 \mathrm{E}-02$ & Trabid \\
\hline 104169_at & zinc finger protein of the cerebellum 1 & -2.2 & $8.91 \mathrm{E}-03$ & Zic1 \\
\hline 160824_at & RIKEN CDNA 1110037N09 gene & -2.2 & $4.57 \mathrm{E}-03$ & 1110037N09Rik \\
\hline
\end{tabular}

MUT indicates HIF-1 $\alpha^{\Delta / \Delta}$; Avg ratio (FC) indicates the average fold change; Avg chg $p$ value is the $p$ value (paired, two-tailed) calculated using the nonparametric Wilcoxon's signed rank test (relative); genes involved in apoptotic pathways are in bold.

Table 5. Genes expressed in opposite directions after hypoxia in $H I F-1 \alpha^{F / F}$ and $H I F-1 \alpha^{\Delta / \Delta}$

\begin{tabular}{llll}
\hline Probe set & Gene title & Avg ratio (FC) (WT:MUT) & Avg chg $p$ value (WT:MUT) \\
\hline 104217_at & RIKEN cDNA 1110015E22 gene & $-2.1: 2.6$ & 2.09e-2:1.05e-2 \\
\hline
\end{tabular}

WT indicates HIF- $1 \alpha^{F / F}$; MUT indicates HIF-1 $\alpha^{\Delta / \Delta}$; Avg ratio (FC) indicates the average fold change; Avg chg $p$ value is the $p$ value (paired, two-tailed) calculated using the nonparametric Wilcoxon's signed rank test (relative).

the genes in the classically defined HIF-dependent signaling pathways are activated, suggesting that there is functional redundancy in vivo. Although functional redundancy seems to preserve most of the classically defined transcriptional responses to hypoxia, this cannot explain the clear phenotype of neuroprotection seen in the absence of $H I F-1 \alpha$. Therefore, we focused on the genes uniquely changed in the $H I F-1 \alpha^{\Delta / \Delta}$ mice.

Using the Gene Ontology Tree Machine program (http:// genereg.ornl.gov/gotm; University of Tennessee and Oak Ridge National Laboratory) (Zhang et al., 2004), we asked whether any of the genes that were differentially regulated between $H I F-1 \alpha^{F / F}$ and HIF-1 $\alpha^{\Delta / \Delta}$ mice in response to hypoxia (Fig. $4 C$ ) belonged to a functional category that could explain the phenotype of neuroprotection. Interestingly, this analysis showed that genes involved in apoptosis pathways with significance of enrichment $\left({ }^{*} p<\right.$ 0.02 ) were downregulated in the HIF-1 $\alpha^{\Delta / \Delta}$ mice and revealed genes that may contribute to the observed phenotype. Additional analysis using PubMed revealed several other genes involved in the apoptotic pathways that were also uniquely downregulated in the HIF-1 $\alpha^{\Delta / \Delta}$ mice (see Discussion) (Table 4, genes in bold).

\section{Discussion}

Our results demonstrate that lack of HIF- $1 \alpha$ leads to neuroprotection in acute ischemic insult. Using a conditional knock-out combined with BCCAo, we were clearly able to demonstrate the role of HIF- $1 \alpha$ in the response of the brain to hypoxia and show that loss of HIF- $1 \alpha$ in the brain is neuroprotective. We also show that the gene-expression response to hypoxia also differs in the absence of HIF- $1 \alpha$; specifically, apoptotic genes are downregulated in the HIF-1 $\alpha^{\Delta / \Delta}$ mice. Conversely, we find that neuroprotective genes [VEGF and growth arrest and DNA damageinducible 45 protein $(G A D D 45)$ ] are regulated similarly in the presence or absence of HIF-1 $\alpha$, suggesting that there is functional redundancy of their control with another transcription factor besides HIF- $1 \alpha$.

Our data suggest that acute activation of HIF- $1 \alpha$ in the brain may be deleterious, and this is avoided in the HIF- $1 \alpha$ knock-out mice.
Previous work has focused on the more chronic stimulation of HIF- $1 \alpha$ as being important in ischemic preconditioning for the induction of genes that promote angiogenesis, growth factor stimulation, and glycolytic metabolism, resulting in the survival of cells exposed to hypoxia (Bergeron et al., 2000; Marti et al., 2000; Digicaylioglu and Lipton, 2001; Stenzel-Poore et al., 2003). However, there are isolated reports suggesting that neuronal cell death in culture models may be promoted by interactions between HIF- $1 \alpha$ and p53 (Halterman and Federoff, 1999; Halterman et al., 1999; Goda et al., 2003; Renton et al., 2003). Consistent with this idea, we noted that $H I F-1 \alpha^{\Delta / \Delta}$ animals had genes involved in apoptotic pathways that were uniquely downregulated compared with $H I F-1 \alpha^{F / F}$ animals. These genes encode cytotoxic granule-associated RNA binding protein-like 1 (Tial1), cytotoxic granule-associated RNA binding protein-1 (Tia1), and splicing factor, arginine/serine-rich 7 (Sfrs7). Tial1 is an RNA-recognition motif-type RNA-binding protein that has been implicated as a mediator of apoptosis and is induced during ischemia in the brain and during hypoxia in astrocytes and neurons (Taupin et al., 1995; Jin et al., 2000). It is interesting to speculate that these and other proapoptotic genes may be responsible for promoting the apoptotic response to hypoxia in normal cells, perhaps through the proposed p53/HIF- $1 \alpha$ interactions (Halterman and Federoff, 1999; Halterman et al., 1999; Goda et al., 2003; Renton et al., 2003) that may promote apoptosis, and that specific disruption of these interactions (attributable to lack of HIF-1 $\alpha$ ) lead to downregulation and loss of expression of genes that promote cell death in the mutant animals.

Although the role of HIF- $1 \alpha$ has been extensively characterized in vitro, this is the first study to evaluate the role of HIF- $1 \alpha$ in vivo in the brain in response to acute hypoxia/ischemia. In contrast to in vitro results, we find that the phenotype and transcriptional response to hypoxia in vivo is much more complex than would have been anticipated based on the cell culture results. In addition, most of the observed changes in gene expression in the brain in response to hypoxia are not entirely HIF- $1 \alpha$ dependent. Biological network analysis using Ingenuity Pathway Analysis demonstrates 
signaling through putative HIF- $1 \alpha$-dependent genes regardless of whether HIF- $1 \alpha$ is present. We find that the majority of genes that were induced in response to hypoxia (i.e., the average signal intensity: p21, WT, $235.1 \pm 10.3$ vs mutant, $263.9 \pm 22.1$; GADD45, WT, $120.3 \pm 13.7$ vs mutant, $121.0 \pm 3.5$; and VEGF, WT, $139.7 \pm 16.6 \mathrm{vs}$ mutant, $118.8 \pm 35.8$ ) were increased to a similar degree in both the WT and mutant animals (Table 2). This finding was further confirmed using quantitative PCR for p21 (average fold change, WT, $7.72 \pm 0.65$ vs mutant, $9.27 \pm 2.05$ ), which we have shown previously is dependent on HIF- $1 \alpha$ for transcriptional induction in response to hypoxia in mouse embryonic fibroblasts and in B-cells, in which deletion of the floxed allele was $\sim 90 \%$ (Goda et al., 2003). Hence, it is more likely that the brain has multiple ways of inducing genes involved in the response to hypoxia potentially through HIF-2. The molecular evidence that we obtained for this conclusion based on our genomic study is not completely unexpected, because there are recent data suggesting that HIF- $1 \alpha$ is not the only protein driving the transcriptional response to hypoxia (Wiesener et al., 1998, 2003; Brusselmans et al., 2003; Hu et al., 2003). These findings are very intriguing given that our studies are based on the whole animal and whole tissue phenotype in response to a pathophysiologically relevant level of hypoxia/ischemia, and it will be interesting to delineate what the secondary pathways are for activation of these genes in response to acute brain hypoxia.

In conclusion, although the role of HIF- $1 \alpha$ has been extensively characterized in vitro, this is the first study to evaluate the role of HIF- $1 \alpha$ in vivo in the adult brain in response to hypoxia/ ischemia. Our findings clearly demonstrate that deletion of HIF- $1 \alpha$ in the brain leads to an amelioration of apoptosis in the nervous system of the adult mouse.

\section{References}

Barlow C, Hirotsune S, Paylor R, Liyanage M, Eckhaus M, Collins F, Shiloh Y, Crawley JN, Ried T, Tagle D, Wynshaw-Boris A (1996) Atm-deficient mice: a paradigm of ataxia telangiectasia. Cell 86:159-171.

Berg JT, Breen EC, Fu Z, Mathieu-Costello O, West JB (1998) Alveolar hypoxia increases gene expression of extracellular matrix proteins and platelet-derived growth factor-B in lung parenchyma. Am J Respir Crit Care Med 158:1920-1928.

Bergeron M, Gidday JM, Yu AY, Semenza GL, Ferriero DM, Sharp FR (2000) Role of hypoxia-inducible factor-1 in hypoxia-induced ischemic tolerance in neonatal rat brain. Ann Neurol 48:285-296.

Brusselmans K, Compernolle V, Tjwa M, Wiesener MS, Maxwell PH, Collen D, Carmeliet P (2003) Heterozygous deficiency of hypoxia-inducible factor2alpha protects mice against pulmonary hypertension and right ventricular dysfunction during prolonged hypoxia. J Clin Invest 111:1519-1527.

Bunn HF, Poyton RO (1996) Oxygen sensing and molecular adaptation to hypoxia. Physiol Rev 76:839-885.

Caceres M, Lachuer J, Zapala MA, Redmond JC, Kudo L, Geschwind DH, Lockhart DJ, Preuss TM, Barlow C (2003) Elevated gene expression levels distinguish human from non-human primate brains. Proc Natl Acad Sci USA 100:13030-13035.

Cervos-Navarro J, Diemer NH (1991) Selective vulnerability in brain hypoxia. Crit Rev Neurobiol 6:149-182.

Digicaylioglu M, Lipton SA (2001) Erythropoietin-mediated neuroprotection involves cross-talk between Jak 2 and NF- $\kappa \mathrm{B}$ signaling cascades. Nature 412:641-647.

Dragatsis I, Zeitlin S (2000) CaMKIIalpha-Cre transgene expression and recombination patterns in the mouse brain. Genesis 26:133-135.

Fujii M, Hara H, Meng W, Vonsattel JP, Huang Z, Moskowitz MA (1997) Strain-related differences in susceptibility to transient forebrain ischemia in SV-129 and C57black/6 mice. Stroke 28:1805-1811.

Goda N, Ryan HE, Khadivi B, McNulty W, Rickert RC, Johnson RS (2003) Hypoxia-inducible factor 1alpha is essential for cell cycle arrest during hypoxia. Mol Cell Biol 23:359-369.

Halterman MW, Federoff HJ (1999) HIF-1alpha and p53 promote hypoxia- induced delayed neuronal death in models of CNS ischemia. Exp Neurol 159:65-72.

Halterman MW, Miller CC, Federoff HJ (1999) Hypoxia-inducible factor- $1 \alpha$ mediates hypoxia-induced delayed neuronal death that involves p53. J Neurosci 19:6818-6824.

Hu CJ, Wang LY, Chodosh LA, Keith B, Simon MC (2003) Differential roles of hypoxia-inducible factor 1alpha (HIF-1alpha) and HIF-2alpha in hypoxic gene regulation. Mol Cell Biol 23:9361-9374.

Jin K, Li W, Nagayama T, He X, Sinor AD, Chang J, Mao X, Graham SH, Simon RP, Greenberg DA (2000) Expression of the RNA-binding protein TIAR is increased in neurons after ischemic cerebral injury. J Neurosci Res 59:767-774.

Marti HJ, Bernaudin M, Bellail A, Schoch H, Euler M, Petit E, Risau W (2000) Hypoxia-induced vascular endothelial growth factor expression precedes neovascularization after cerebral ischemia. Am J Pathol 156:965-976.

Papadopoulos MC, Verkman AS (2005) Aquaporin-4 gene disruption in mice reduces brain swelling and mortality in pneumococcal meningitis. J Biol Chem 280:13906-13912.

Renton A, Llanos S, Lu X (2003) Hypoxia induces p53 through a pathway distinct from most DNA-damaging and stress-inducing agents. Carcinogenesis 24:1177-1182.

Ryan HE, Lo J, Johnson RS (1998) HIF-1 alpha is required for solid tumor formation and embryonic vascularization. EMBO J 17:3005-3015.

Ryan HE, Poloni M, McNulty W, Elson D, Gassmann M, Arbeit JM, Johnson RS (2000) Hypoxia-inducible factor-1alpha is a positive factor in solid tumor growth. Cancer Res 60:4010-4015.

Sandberg R, Yasuda R, Pankratz DG, Carter TA, Del Rio JA, Wodicka L, Mayford M, Lockhart DJ, Barlow C (2000) Regional and strain-specific gene expression mapping in the adult mouse brain. Proc Natl Acad Sci USA 97:11038-11043.

Semenza GL (2000) Expression of hypoxia-inducible factor 1: mechanisms and consequences. Biochem Pharmacol 59:47-53.

Stenzel-Poore MP, Stevens SL, Xiong Z, Lessov NS, Harrington CA, Mori M, Meller R, Rosenzweig HL, Tobar E, Shaw TE, Chu X, Simon RP (2003) Effect of ischaemic preconditioning on genomic response to cerebral ischaemia: similarity to neuroprotective strategies in hibernation and hypoxia-tolerant states. Lancet 362:1028-1037.

Taupin JL, Tian Q, Kedersha N, Robertson M, Anderson P (1995) The RNA-binding protein TIAR is translocated from the nucleus to the cytoplasm during Fas-mediated apoptotic cell death. Proc Natl Acad Sci USA 92:1629-1633.

Tomita S, Ueno M, Sakamoto M, Kitahama Y, Ueki M, Maekawa N, Sakamoto H, Gassmann M, Kageyama R, Ueda N, Gonzalez FJ, Takahama Y (2003) Defective brain development in mice lacking the Hif-1alpha gene in neural cells. Mol Cell Biol 23:6739-6749.

Wang YF, Tsirka SE, Strickland S, Stieg PE, Soriano SG, Lipton SA (1998) Tissue plasminogen activator (tPA) increases neuronal damage after focal cerebral ischemia in wild-type and tPA-deficient mice. Nat Med 4:228-231.

Wenger RH (2002) Cellular adaptation to hypoxia: O2-sensing protein hydroxylases, hypoxia-inducible transcription factors, and O2-regulated gene expression. FASEB J 16:1151-1162.

Wiesener MS, Turley H, Allen WE, Willam C, Eckardt KU, Talks KL, Wood SM, Gatter KC, Harris AL, Pugh CW, Ratcliffe PJ, Maxwell PH (1998) Induction of endothelial PAS domain protein- 1 by hypoxia: characterization and comparison with hypoxia-inducible factor-1alpha. Blood 92:2260-2268.

Wiesener MS, Jurgensen JS, Rosenberger C, Scholze CK, Horstrup JH, Warnecke C, Mandriota S, Bechmann I, Frei UA, Pugh CW, Ratcliffe PJ, Bachmann S, Maxwell PH, Eckardt KU (2003) Widespread hypoxiainducible expression of HIF-2alpha in distinct cell populations of different organs. FASEB J 17:271-273.

Wodicka L, Dong H, Mittmann M, Ho MH, Lockhart DJ (1997) Genomewide expression monitoring in Saccharomyces cerevisiae. Nat Biotechnol 15:1359-1367.

Zapala MA, Lockhart DJ, Pankratz DG, Garcia AJ, Barlow C (2002) Software and methods for oligonucleotide and cDNA array data analysis. Genome Biol 3:SOFTWARE0001.

Zhang B, Schmoyer D, Kirov S, Snoddy J (2004) GOTree Machine (GOTM): a web-based platform for interpreting sets of interesting genes using Gene Ontology hierarchies. BMC Bioinformatics 5:16. 